\title{
PENGARUH PERILAKU PENJUALAN DAN PELAYANAN OUTLET TERHADAP KINERJA PENJUALAN PT COCA - COLA CABANG PADANG
}

\author{
Ratih Mustika Sari, Febsri Susanti \\ Sekolah Tinggi Ilmu Ekonomi "KBP" \\ febsrisusanti@akbpstie.ac.id
}

\begin{abstract}
The purpose of this study to analyze the influence of sales behavior and service outlets partially and simultaneously to the sales performance of PT. Coca-Cola Branch of Padang. The research method used is quantitative descriptive. Sampling technique used is non probability sampling method with accidental sampling so that the population is taken as many as 100 respondents, the data collection method used is observation, questionnaire and literature review. Data analysis techniques used were classical assumptions, multiple linear regression, $t$ test, $F$ test and detemination coefficients. Based on multiple regression analysis, sales behavior variable and outlet service to sales behavior in get $Y=2,973+$ $0,427 X 1+0,183 X 2+e$. From $t$ test conducted got sales behavior and service outlet have a significant and positive impact to sales performance of PT. CocaCola Branch Padang with significant value <0,05. From the results of $F$ test proved that the variable behavior of sales and service outlets simultaneously have a significant and positive impact on the sales performance of PT. Coca-Cola Branch of Padang, while the result of coefficient of determination obtained by free variable contribution explain dependent variable equal to $13,5 \%$ is $86,5 \%$, explained by other variable not used in this research.
\end{abstract}

Keywords: Sales Behavior, outlet service and sales performance.

\section{PENDAHULUAN}

Perusahaan Coca-Cola merupakan salah satu perusahaan minuman yang cukup mendunia dengan penguasaan pasar yang sudah cukup merata diseluruh dunia. Produk-produk minuman dari perusahaan Coca-Cola tersebut seperti Sprite, Fanta, dan berbagai produk minuman baru yang beredar dipasaran.

Sebagai perusahaan minuman terbesar di dunia, perusahaan Coca-Cola tidak hanya memiliki banyak keunggulan, namun juga mulai muncul sisi kelemahannya yang berindikasi pada larinya para konsumen meninggalkan produk minuman dari perusahaan tersebut. Peruahaan Coca-Cola memiliki beberapa kelemahan diantaranya adalah bentuk inovasi serta ekspansi yang lambat dari perusahaan dalam mengatasi pesaing serta upaya memenuhi keinginan dari pasar yang terus 
meningkat. Masalah lainnya adalah menurunnya konsumsi pasar terhadap produk minuman berkarbonasi.

Upaya yang selalu dilakukan oleh perusahaan Coca-Cola adalah dengan melakukan inovasi dan perubahan setiap tahun terhadap iklan dan inovasi icon terhadap kemasan minuman maupun slogan-slogan yang ada, perubahan dan inovasi tersebut diharapkan dapat meningkatkan minat dan keputusan pembeli terhadap minuman Coca-Cola. Selain itu perusahaan Coca-Cola juga selalu mempertahankan kualitas produk minuman yang dihasilkan dengan quality control perusahaan.

Permasalahan yang dihadapi Coca-Cola pada saat ini adalah bertahan di tengah peralihan konsumen yang mulai meninggalkan minuman berkarbonasi dan bersoda beralih kejenis minuman lain yang menjaga kesehatan.

Penjualan paling besar terdapat pada tahun 2014 yaitu11.548.423pcs, kemudian pada tahun berikutnya yaitu tahun 2015 dan 2016 penjualan mengalami penurunan sebesar 669.259 pcs. Dengan data diatas, maka dapat dikatakan bahwa ada masalah di perusahaan Coca-Cola.

Kecamatan Padang Utara merupakan daerah dimana terdapat pusat-pusat perbelanjaan dan mini market yang menyediakan minuman-minuman ringan seperti Coca-Cola. Pangsa pasar minuman Coca-Cola di kecamatan Padang Utara merupakan daerah kos-kosan, mahasiswa maupun karyawan, dikarenakan di Padang Utara terdapat beberapa Sekolah dan Kampus. Berdasarkan pengamatan peneliti pada salah satu minimarket dalam 2 jam terlihat terdapat 10 konsumen yang membeli minuman Coca-Cola.

Berdasarkan latar belakang tersebut maka peneliti ingin meneliti lebih jauh tentang. Pengaruh Perilaku Penjualan dan Pelayanan Outlet Terhadap Kinerja Penjualan Pada PT. Coca - Cola Cabang Padang.

Perumusan Masalah

1. Bagaimana Pengaruh Perilaku Penjualan terhadap Kinerja Penjualan pada PT.Coca-Cola cabang Padang.

2. Bagaimana Pengaruh Pelayanan Outlet terhadap Kinerja Penjualan pada PT. Coca-Cola cabang Padang.

Tujuan Penelitian

1. Menganalisis Pengaruh Perilaku Penjualan terhadap Kinerja Penjualan pada PT.Coca-Cola cabang Padang.

2. Menganalisa Pengaruh Pelayanan Outlet terhadap Kinerja Penjualan pada PT.Coca-Cola cabanag Padang.

\section{LANDASAN TEORI}

\section{Kinerja Penjualan}

Menurut Miner dalam Sutrisno (2013:170), kinerja adalah bagaimana seseorang diharapkan dapat berfungsi dan berperilaku sesuai dengan tugas yang telah dibebankan kepadanya. Setiap harapan mengenai bagaimana seseorang harus berperilaku dalam melaksanakan tugas, berarti menunjukkan suatu peran dalam organisasi.

Menurut Miner dalam Sutrisno $(2013 ; 172)$, indikator kinerja karyawan dapat digunakan empat aspek dari kinerja yaitu sebagai berikut: 
1. Kualitas yang dihasilkan, menerangkan tentang jumlah kesalahan, waktu, dan ketepatan dalam melakukan tugas.

2. Kuantitas yang dihasilkan, berkenaan dengan berapa jumlah prosuk atau jasa yang dihasilkan.

3. Waktu kerja, menerangkan akan jumlah absen, keterlambatan, serta masa kerja yang telah dijalani individu pegawai tersebut.

4. Kerja sama, menerangkan akan bagaimana individu membantu atau menghambat usaha dari teman sekerjanya.

\section{Perilaku Penjualan}

Menurut Marliani (2015:27) perilaku adalah tindakan atau aktivitas dari manusia yang mempunyai bentangan yang sangat luas, seperti berjalan, berbicara, menangis, tertawa, bekerja, kuliah, menulis membaca dan sebagainya.

Menurut Marliani (2015:42), perilaku individu dapat dipengaruhi oleh effort (usaha) ability (kemampuan) dan situasi lingkungan.

1. Affort (usaha), adalah usaha individu dalam bentuk motivasi. Motivasi adalah kekuatan yang dimiliki seseorang dalam yang menimbulkan intensitas dan ketekunan yang dilakukan secara sukarela.

2. Ability (kemampuan), kemampuan seorang individu dalam bentuk kompetensi, individu yang kompeten memiliki pengetahuan dan keahlian.

3. Situasi lingkungan, lingkungan dapat memberikan dampak positif ataupun negatif. Situasi yang kondusif, misalnya dukungan dari atasan, teman kerja, sarana dan prasarana yang memadai, dan lain-lain.

\section{Layanan Outlet}

Menurut Lupiyoadi (2013:197), layanan pelanggan meliputi berbagai aktifitas diseluruh area bisnis yang berusaha mengombinasikan mulai dari pemesanan, pemprosesan hingga pemberian hasil jasa melalui komunikasi untuk mempererat kerja sama dengan pelanggan

Menurut Parasuraman et, al dalam Tjiptono (2012:198), mengidentifikasi 10 dimensi pokok pelayanan, yang dapat digunakan sebagai indikator yaitu sebagai berikut:

1. Reliabilitas, mencakup dua aspek utama yaitu konsitensi kinerja (performance) dan sifat terpecaya (dependability).

2. Responsivitas atau daya tanggap yaitu kesedian dan kesiapan para pegawai untuk membantu dan melayani para pelanggan dengan segera.

3. Kompetensi yaitu penguasaan keterampilan dan pengetahuan yang dibutuhkan agar dapat melayani sesuai dengan kebutuhan pelanggan.

4. Akses yaitu kemudahan untuk dihubungi atau ditemui (approacbility) dan kemudahan kontak.

5. Kesopanan (coustesy) yaitu meliputi sikap santun, respek, atensi, dan keramahan para karyawan kontak (seperti resepsionis, operator telepon, bell person, teller bank dll).

6. Komunikasi artinya menyampaikan informasi kepada para pelanggan dalam bahasa yang mudah mereka pahami, serta selalu mendengarkan saran dan keluhan pelanggan.

7. Kredibilitas yaitu sifat jujur dan dapat dipercaya.

8. Keamanan (security) yaitu bebas dari bahaya risiko atau keragu-raguan. 
9. Kemampuan memahami pelanggan yaitu berupa memahami pelanggan dan kebutuhan spesifik mereka, memberikan perhatian individual, dan mengenal pelanggan regular.

10. Bukti fisik yaitu penampilan fasilitas fisik, peralatan, personil, dan bahanbahan komunikasi pemasaran

\section{METODE PENELITIAN}

\section{Populasi dan Sampel}

Populasi dalam penelitian ini adalah otlet Coca-cola Padang Utara yang berjumlah 2,855 outlet.

Teknik pengambilan sampel yang di gunakan dalam penelitian ini adalah melalui non probability sampling. Berdasarkan teknik ini, tidak semua individu mendapat peluang yang sama untuk diambil sebagai sampel. Sedangkan metodenya melalui accidental sampling yaitu mereka yang dijumpai peneliti ditempat penelitian

Berdasarkan perhitungan menggunakan rumus Slovin di atas, maka jumlah sampel dalam penelitian ini sebesar 100 outlet.

\section{Teknik Analisis Data}

Setelah data-data terkumpul selanjutnya dilakukan analisis data sebagai berikut :

\section{Uji validitas}

Uji validitas digunakan untuk mengukur sah atau valid tidaknya suatu kuesioner. Penguji validitas tiap butir digunakan analisa item, yaitu mengkorelasikan skor tiap butir dengan skor total yang merupakan jumlah tiap butir (corrected item total correlation). Validnya sebuah ditentukan dari nilai koefisien kolerasi yang dihasilkan besar dari 0,30 dan dapat digunakan untuk selanjutnya (Sugiono, 2014).

\section{Uji Reliabilitas}

Uji reliabilitas adalah alat untuk mengukur suatu kuesioner yang mempunyai indikator dari variabel atau konstruk dengan uji statistik Cronbach Alpha (a). Suatu konstruk atau variabel dikatakan reliabel jika memberikan nilai Cronbanch Alpha > 0,600 (Ghozali, 2007: 48).

\section{Analisis Deskriptif}

Analisis ini bermaksud untuk menggambarkan karakteristik masing-masing variabel penelitian.

\section{Asumsi Klasik}

\section{a. Uji Normalitas}

Menurut Sugiyono (2007) uji normalitas digunakan untuk mengetahui apakah populasi data berdistribusi normal atau tidak dengan uji lilliefors dengan melihat nilai pada Kolmogorov-Smimov. Data dinyatakan berdistribusi normal jika signifikansi lebih besar dari 0,05.

\section{b. Uji Multikolonieritas}

Uji multikolonieritas bertujuan untuk menguji apakah dalam model regresi ditemukan adanya korelasi antar variabel bebas. Besarnya Variabel Inflation Faktor (VIF), pedoman suatu model regresi yang bebas tidak mengandung 
multikolonieritas yaitu nilai VIF $\leq 10$. Besarnya Tolerance pedoman suatu model regresi yang bebas mengandung multikolonieritas yaitu nilai Tolerance $>0,10$.

\section{c. Uji Heterkesdatisitas}

Menurut Priyatno (2010:83), heteroskesdatisitas adalah keadaan dimana terjadi ketidaksamaan varian dari residual untuk semua pengamatan pada model regresi. Uji heteroskesdatisitas dapat menggunakan Uji Glejser dengan nilai signifikan < 0,05 maka terjadi masalah heteroskesdatisitas. Uji heteroskesdatisitas ini dapat menggunakan menggunakan program SPSS Versi 20.0.

\section{Analisi Regresi Linear Berganda}

Menurut Ghozali (2007), analisis regeresi linear berganda digunakan untuk menganalisis pengaruh beberapa variabel bebas atau variabel independen (X) terhadap satu variabel terikat atau variabel dependen $(\mathrm{Y})$ secara bersama-sama.

$\mathrm{Y}=\mathrm{a}+\mathrm{b}_{1} \mathrm{X}_{1}+\mathrm{b}_{2} \mathrm{X}_{2}+\mathrm{e}$

Keterangan:

$\mathrm{Y} \quad=$ Kinerja Penjualan

$\mathrm{a}=$ Konstanta

$\mathrm{X}_{1}=$ Perilaku Penjualan

$\mathrm{X}_{2}=$ Layanan Outlet

$\mathrm{b}_{1}=$ Koefisien regresi

$\mathrm{b}_{2}=$ Koefisien regresi

$\mathrm{e}=$ Standar error

\section{Uji F}

Menurut Ghozali (2007), uji F pada dasarnya menunjukkan apakah semua variabel bebas yang dimasukkan dalam model mempunyai pengaruh secara bersama-sama terhadap variabel terikat. Uji ini dilakukan dengan membandingkan signifikansi nilai $F_{\text {hitung }}>F_{\text {tabel }}$ maka model yang dirumuskan sudah tepat Uji t

Menurut Ghozali (2007), uji parsial digunakan untuk menguji signifikansi hubungan antara variabel $\mathrm{X}$ dan variabel $\mathrm{Y}$, apakah variabel $\mathrm{X}$ benar-benar berpengaruh terhadap variabel $\mathrm{Y}$ secara individu.

\section{$\mathbf{U j i} \mathbf{R}^{2}$}

Menurut Riduwan (2009), koefisien determinasi $\left(\mathrm{R}^{2}\right)$ digunakan untuk mengetahui berapa besar kontribusi variabel bebas $(\mathrm{X})$ yaitu perilaku penjual $\left(\mathrm{X}_{1}\right)$ pelayanan outlet $\left(\mathrm{X}_{2}\right)$ terhadap variabel terikat $(\mathrm{Y})$ yaitu kinerja penjual. Koefisien determinasi adalah kuadrat koefisien korelasi. 


\section{HASIL PENELITIAN DAN PEMBAHASAN}

\section{Uji Regresi Linear Berganda}

Tabel 1

Hasil Uji Regresi Linear Berganda

\section{Coefficients $^{\mathrm{a}}$}

\begin{tabular}{|c|c|c|c|c|c|}
\hline \multirow[b]{2}{*}{ Model } & \multicolumn{2}{|c|}{$\begin{array}{c}\text { Unstandardized } \\
\text { Coefficients }\end{array}$} & \multirow{2}{*}{$\begin{array}{c}\text { Standardized } \\
\text { Coefficients }\end{array}$} & \multirow[b]{2}{*}{$\mathrm{T}$} & \multirow[b]{2}{*}{ Sig. } \\
\hline & B & Std. Error & & & \\
\hline (Constant) & 2,973 & 6,416 & &, 463 &, 644 \\
\hline Perilaku_Penjualan & ,427 &, 120 & ,332 & $\begin{array}{r}3,54 \\
3\end{array}$ & ,001 \\
\hline Layanan_Outlet &, 183 & ,075 & ,227 & $\begin{array}{r}2,42 \\
8\end{array}$ & ,017 \\
\hline
\end{tabular}

a. Dependent

Variable:

KinerjaKaryawan

$\mathrm{Y}=2,973+0,427 \mathrm{X}_{1}+0,183 \mathrm{X}_{2}+\mathrm{e}$

Persamaan regresi di atas memperlihatkan hubungan antara variabel independen dengan variabel dependen secara parsial, dari persamaan tersebut dapat diambil kesimpulan bahwa :

1) Nilai constanta adalah $=2,973$ artinya jika tidak terjadi perubahan variabel perilaku penjualan dan layanan outlet (nilai $X_{1}$ dan $X_{2}$ adalah 0) maka kinerja penjualan PT. Coca-Cola Cabang Padang tetap sebesar 2,973 satuan.

2) Nilai koefisien regresi perilaku penjualan adalah $=0,427$ artinya jika variabel perilaku penjualan $\left(\mathrm{X}_{1}\right)$ meningkat sebesar 1 (satuan) dengan asumsi variabel layanan outlet $\left(\mathrm{X}_{2}\right)$ dan konstanta (a) adalah 0 (nol), maka kinerja penjualan PT. Coca-Cola Cabang Padang meningkat sebesar 0,427 satuan.

3) Nilai koefisien regresi layanan outlet adalah $=0,183$ artinya jika variabel layanan outlet $\left(\mathrm{X}_{2}\right)$ meningkat sebesar 1 (satuan) dengan asumsi variabel perilaku penjualan $\left(\mathrm{X}_{1}\right)$ dan konstanta (a) adalah 0 (nol), maka kinerja penjualan PT. Coca-Cola Cabang Padang meningkat sebesar 0,183 satuan.

\subsection{Uji Hipotesis}

\subsubsection{Uji F}

Uji $\mathrm{F}$ digunakan untuk mengetahui pengaruh semua variabel bebas secara bersama-sama terhadap nilai variabel terikat. Berdasarkan uji $\mathrm{F}$ yang dilakukan dapat dilihat pada Tabel di bawah ini: 
Tabel 2

Hasil Uji F

ANOVA $^{\text {b }}$

\begin{tabular}{|l|r|r|r|c|c|}
\hline Model & Sum of Squares & Df & Mean Square & F & Sig. \\
\hline 1 Regression & 533,552 & 2 & 266,776 & 8,708 &, $000^{\mathrm{b}}$ \\
Residual & 2971,808 & 97 & 30,637 & & \\
Total & 3505,360 & 99 & & & \\
\hline
\end{tabular}

Berdasarkan hasil pengujian pada tabel di atas dapat dilihat pada nilai $\mathrm{F}_{\text {hitung }}$ sebesar 8,708 dengan nilai signifikan $<0,05$ maka Ho ditolak dan $\mathrm{H}_{\mathrm{a}}$ diterima. Sehingga dapat disimpulkan bahwa variabel perilaku penjualan $\left(\mathrm{X}_{1}\right)$ dan layanan outlet $\left(\mathrm{X}_{2}\right)$ secara bersamaan berpengaruh signifikan terhadap kinerja penjualan PT. Coca-Cola Cabang Padang.

\section{Uji t}

Koeefisien regresi bertujuan untuk mengetahui apakah variabel bebas yang terhadap dalam persamaan secara individu berpengaruhterhadap nilai variabel terikat. Berdasarkan uji t yang dilakukan dapat dilihat pada Tabel 3 di bawah ini:

\section{Tabel 3}

\section{Hasil Uji t}

\section{Coefficients $^{\mathrm{a}}$}

\begin{tabular}{|l|r|r|r|r|r|}
\hline \multirow{2}{*}{ Model } & \multicolumn{2}{|c|}{$\begin{array}{c}\text { Unstandardized } \\
\text { Coefficients }\end{array}$} & $\begin{array}{c}\text { Standardized } \\
\text { Coefficients }\end{array}$ & \multirow{2}{*}{} & \multirow{2}{*}{ Sig. } \\
\cline { 2 - 4 } & \multicolumn{1}{|c|}{ B } & Std. Error & \multicolumn{1}{c|}{ Beta } & \multicolumn{1}{c|}{ T } & \multicolumn{1}{c|}{ Sig } \\
\hline 1 (Constant) & 2,973 & 6,416 & &, 463 &, 001 \\
Perilaku_Penjualan &, 427 &, 120 &, 332 & 3,543 &, 017 \\
Layanan_Outlet &, 183 &, 075 &, 227 & 2,428 &, \\
\hline
\end{tabular}

Berdasarkan hasil yang yang dilakukan pada tabel 3 dapat diketahui bahwa apabila nilai $t_{\text {hitung }}>t_{\text {tabel }}$ dan nilai signifikan $<0,05$, maka dapat dikatakan bahwa variabel bebas tersebut berpengaruh signifikan secara individu terhadap variabel terikat.

\section{Uji Koefisien Determinasi $\left(\mathbf{R}^{2}\right)$}

\section{Tabel 4}

\section{Hasil Uji Koefisien Determinasi}

Model Summary

\begin{tabular}{|c|c|c|c|c|c|c|c|c|c|}
\hline \multirow[b]{2}{*}{ Model } & \multirow[b]{2}{*}{$\mathrm{R}$} & \multirow[b]{2}{*}{$\begin{array}{c}\mathrm{R} \\
\text { Square }\end{array}$} & \multirow[b]{2}{*}{$\begin{array}{l}\text { Adjusted } \\
\text { R Square }\end{array}$} & \multirow{2}{*}{$\begin{array}{l}\text { Std. Error } \\
\text { of the } \\
\text { Estimate }\end{array}$} & \multicolumn{5}{|c|}{ Change Statistics } \\
\hline & & & & & $\begin{array}{c}\text { R Square } \\
\text { Change }\end{array}$ & F Change & df1 & df2 & $\begin{array}{c}\text { Sig. F } \\
\text { Change }\end{array}$ \\
\hline 1 &, $390^{\mathrm{a}}$ &, 152 & 135 & 5,535 & 152 & 8,708 & 2 & 97 &, 000 \\
\hline
\end{tabular}


Berdasarkan Tabel 4 dapat diketahui bahwa nilai koefisien determinasi terdapat pada nilai Adjusted $R$ Square dengan sebesar 0,135. Hal ini berarti kontribusi variabel bebas dalam menjelaskan variabel terikat adalah sebesar 13,5\% (100-13,5\%) sisanya $86,5 \%$ dijelaskan oleh variabel lain yang tidak dibahas dalam penelitian ini.

\section{PEMBAHASAN HASIL PENELITIAN}

\section{1) Pengaruh Perilaku Penjualan Terhadap Kinerja Penjualan.}

Dari hasil analisis uji hipotesa pada tingkat kepercayaan $\alpha=5 \%$ terbukti bahwa variabel perilaku penjualan $\left(\mathrm{X}_{1}\right)$ berpengaruh positif dan signifikan terhadap kinerja penjualan PT. Coca-Cola Cabang Padang dengan nilai $t_{\text {hitung }}$ sebesar 3,543 sedangkan nilai signifikan $<0,05$.

Berdasarkan hasil tersebut dapat disimpulkan bahwa kinerja penjualan PT. CocaCola Cabang Padang dipengaruhi oleh perilaku penjualan, pengaruhnya tersebut dapat diketahui dari indikator affort (usaha), ability (kemampuan) dan situasi lingkungan, namun dari beberapa indikator tersebut yang paling dominan mempengaruhi kinerja penjualan PT. Coca-Cola Cabang Padang adalah kemampuan yang dimiliki oleh tenaga penjual seperti kemampuan yang baik dalam melayani konsumen dan dapat menjawab permasalahan yang terjadi pada konsumen sehingga dengan adanya kemampuan tersebut maka konsumen merasa nyaman melakukan pembelian, yang akhirnya akan berdampak pada keuntungan yang akan didapatkan oleh perusahaan.

Penelitian ini sejalan dengan penelitian yang dilakukan oleh Wihartono (2013) hasil penelitian menunjukan bahwa walaupun sales menerapkan etika perilaku dalam menjualnya sudah baik belum tentu pelanggan dealler nissan Basuki Rahmat Surabaya bisa loyal. Hal ini dikarenakan ketika pelanggan mendapatkan pelayanan yang etis dari penjual, pelanggan merasa belum mengenal sales lebih dekat. Karena pelanggan belum percaya apakah sales tulus atau tidak tulus. Maka etika perilaku penjual tidak bisa secara langsung meningkatkan loyalitas pelanggan.

\section{2) Pengaruh Layanan Outlet Terhadap Kinerja Penjualan.}

Dari hasil analisis uji hipotesa pada tingkat kepercayaan $\alpha=5 \%$ terbukti bahwa variabel layanan outlet $\left(\mathrm{X}_{2}\right)$ berpengaruh positif dan signifikan terhadap kinerja penjualan PT. Coca-Cola Cabang Padang dengan nilai $t_{\text {hitung }}$ sebesar 2,428 sedangkan nilai signifikan $<0,05$.

Berdasarkan hasil tersebut dapat disimpulkan bahwa kinerja penjualan PT. CocaCola Cabang Padang dipengaruhi oleh layanan outlet, pengaruhnya tersebut dapat diketahui dari indikator reliabilitas, responsivitas, kompetensi, akses, kesopanan (coustesy), komunikasi, kredibilitas, keamanan (security), kemampuan memahami pelanggan dan bukti fisik dari beberapa indikator tersebut yang paling dominan mempengaruhi kinerja penjualan PT. Coca-Cola Cabang Padang adalah akses seperti terletak dipusat keramaian dan tidak memiliki waktu tunggu yang lama, dengan memiliki akses yang baik tersebut maka akan mempermudah tenaga penjual dan konsumen untuk mengunjugi PT. Coca-Cola Cabang Padang maupun outlet 
konsumen, sehingga akhirnya keuntungan yang didapatkan oleh perusahaan menjadi meningkat.

Penelitian ini sejalan dengan penelitian Rusdarti (2004) juga menyatakan bahwa pelayanan outlet merupakan salah satu faktor kunci bagi keberhasilan bank sebagai perusahaan jasa dan tidak dapat dipungkiri dalam dunia bisnis saat ini, karena tidak ada yang lebih penting lagi bagi sebuah perusahaan kecuali menempatkan masalah kepuasan dan loyalitas terhadap konsumen melalui pelayanan sebagai salah satu komitmen bisnisnya. Jika pelayanan yang diberikan kepada konsumen itu baik dan memuaskan maka akan mempunyai pengaruh positif terhadap kinerja selling in, sebaliknya apabila pelayanan outlet yang diberikan kepada konsumen kurang memuaskan, maka akan berpengaruh negatif terhadap kinerja selling in.

\section{KESIMPULAN DAN SARAN}

\section{Kesimpulan}

Berdasarkan penelitian yang telah dilakukan, maka dapat ditarik kesimpulan sebagai berikut:

1. Variabel perilaku penjualan berpengaruh secara positif dan signifikan terhadap kinerja penjualan PT. Coca-Cola Cabang Padang dengan nilai thitung sebesar 3,543 sedangkan nilai signifikan $<0,05$.

2. Variabel layanan outlet berpengaruh secara positif dan signifikan terhadap kinerja penjualan PT. Coca-Cola Cabang Padang dengan nilai $\mathrm{t}_{\text {hitung }}$ sebesar 2,428 sedangkan nilai signifikan $<0,05$

\section{Saran}

1. Sebaiknya dalam meningkatkan kinerja penjualan seharusnya tenaga penjual mempertahankan kemampuan yang dimiliki dalam melayani konsumen dan dapat menjawab permasalahan yang terjadi pada konsumen dengan baik sehingga dengan adanya kemampuan tersebut maka konsumen merasa nyaman melakukan pembelian, yang akhirnya akan berdampak pada keuntungan yang akan didapatkan oleh perusahaan

2. Sebaiknya dalam meningkatkan kinerja penjualan perusahaan hendaknya mempertahankan fasilitas yang diberikan seperti terletak dipusat keramaian dan tidak memiliki waktu tunggu yang lama, dengan memiliki akses yang baik tersebut maka akan mempermudah tenaga penjual dan konsumen untuk mengunjugi PT. Coca-Cola Cabang Padang maupun outlet konsumen, sehingga akhirnya keuntungan yang didapatkan oleh perusahaan menjadi meningkat.

3. Bagi peneliti selanjutnya penulis menyarankan, agar memperbanyak jumlah responden yang akan digunakan, serta dilakukan dengan rentang waktu yang lebih lama. Hal ini perlu dilakukan agar hasil yang ditemukan dalam penelitian tersebut akan lebih baik dari penelitian ini. 


\section{DAFTAR PUSTAKA}

Alma, Buchari. 2013. Manajemen Pemasaran dan Pemasaran Jasa. Edisi Revisi. Bandung: Penerbit Alfabeta.

Aziz, N. (2019). Analisis Pengaruh Kualitas Produk, Harga, Promosi Terhadap Keputusan Pembelian Air Minum Dalam Kemasan (AMDK) Merek Aicos Produksi Pt. Bumi Sarimas Indonesia. https://doi.org/10.17605/OSF.IO/8XKYB

Fajar Kustriantomo dan Suryono Budi Santosa. 2015. Pengaruh Strategi Pelayanan Oulet dan Hubungan dengan Outlet Terhadap Kinerja Selling-in Serta dampaknya Terhadap Kinerja Pemasaran Studi Outlet yang menjual Memory Card Sandisk di Semarang. Jurusan Manajemen Fakultas Ekonomika dan Bisnis Universitas Diponegoro. Diponegoro Journal Management. Volume 4, Nomor 2, Tahun 2015, Halaman 1. ISSN (Online): 2337-3792.

Fernandes, Y. D., \& Marlius, D. (2018). Peranan Customer Service Dalam Meningkatkan Pelayanan Kepada Nasabah Pada PT. Bank Pembangunan Daerah Sumatera Barat Cabang Utama Padang. https://doi.org/10.31227/osf.io/wrh3p

Ghozali, Imam. 2007. Aplikasi Analisis Multivariate dengan Program SPSS. Cetakan IV. Semarang: Badan Penerbit Universitas Diponegoro.

Hamali, Arif, Yusuf. 2016. Pemahaman Manajemen Sumber Daya Manusia. Cetak Pertama, Yogyakarta: Buku Seru.

Jehan Reska Alwina. 2010. Pengaruh Keahlian dan Perilaku Penjual Pada Work Outcomes Tenaga Penjualan PT. Karya Dibya Mahardika Regional Jogja, Solo, dan Semarang). Skripsi. Fakultas Ekonomi. Universitas Sebelas Maret. Surakarta.

Kotler, Philip dan Keller, Kevin, Lane. 2015. Manajemen Pemasaran. Edisi 13. Jilid 2. Jakarta: Penerbit: Erlangga.

Linda Novasari. 2006. Analisis Strategi Pelayanan Oulet dan Hubungan Outlet Terhadap Kinerja Selling-in (Studi Pada Tenaga Penjualan PT. Jamu Sido Muncul Kota Semarang). Tesis. Program Studi Magister Manajemen. Program Pasca Sarjana. Universitas Diponegoro. Semarang. 
Lupiyoadi, Rambat. 2013. Manajemen Pemasaran Jasa Berbasis Kompetensi. Edisi 3. Jakarta: Salemba Empat.

Marliani, Rosleny. 2015. Psikologi Industri Organisasi. Cetakan Pertama. Bandung: CV. Pustaka Setia.

Mangkunegara, Anwar, Prabu. 2013. Manajemen Sumber Daya Manusia Perusahaan. Bandung: Remaja Rosdakarya.

Marlius, D. (2018). Loyalitas Nasabah Bank Nagari Syariah Cabang Bukittinggi Dilihat Dari Kualitas Pelayanan. Jurnal Pundi. Volume 1. No. 3. Hal.12-22. https://doi.org/10.31575/jp.v1i3.60

Marlius, D. (2018). Pengaruh Dimensi Kualitas Pelayanan Website Akademik Terhadap Kepuasan Mahasiswa Pada STIE “KBP”. Jurnal Ipteks Terapan. Volume 12. No. 2. Hal. 116-128. http://doi.org/10.22216/jit.2018.v12i2.633

Marlius, D. (2017). Keputusan Pembelian Berdasarkan Faktor Psikologis Dan Bauran Pemasaran Pada PT. Intercom Mobilindo Padang. Jurnal Pundi. Volume 1. No. 1. Hal. 57-66. https://doi.org/10.31575/jp.v1i1.9

Marlius, D. (2016). Pengaruh Bauran Pemasaran Jasa Terhadap Minat Nasabah Dalam Menabung Pada Bank Nagari Cabang Muaralabuh. https://doi.org/10.31227/osf.io/vdqgx

Mayliza, R. (2019). Pengaruh Citra Perusahaan (Corporate Image) Dan Penanganan Keluhan (Complaint Handling) Terhadap Loyalitas Pelanggan (Loyality) Natasha Skin Care Di Kota Padang. https://doi.org/10.17605/OSF.IO/DF9XJ

Moeheriono. 2012. Pengukuran Kinerja berbasis Kompetensi. Jakarta: Raja grafindo Persada Indonesia.

Pardede Ratlan dan Manurung Renhard. 2014. Analisis Jalur/Path Analisis Teori dan Aplikasi Dalam Riset Bisnis. Cetakan Pertama. Jakarta: PT. Rineka Cipta.

Parasuraman, Berry \& Zenthaml. 2008. SERVQUAL: A Multiple-Item Scale for Measuring Consumer Perceptions of Service Quality". Journal of Retailing, Vol. 64, Spring. Jakarta: Rineka cipta.

Priyatno, Duwi. 2010. Pemahaman Analisis Statistik Data Dengan SPSS. Jakarta: PT. Buku Seru.

Riduwan. 2009. Metode dan Teknik Menyusun Tesis. Bandung: Alfabeta. 
Sadermayanti. 2011. Tata Kerja dan Produktivitas Kerja. Bandung: Penerbit Mandar Maju.

Safitri, R. N., \& Marlius, D. (2017). Penerapan E-Banking Dalam Meningkatkan Jasa Dan Layanan Perbankan Di PT. Bank Rakyat Indonesia Cabang Padang. https://doi.org/10.31227/osf.io/gkv8t

Sugiyono. 2014. Metode Penelitian Kuantitatif dan Kualitatif dan R\&D. Bandung: Penerbit Alfabeta.

Sugiyono. 2007. Metode Penelitian Bisnis. Bandung : CV. Alfabeta.

Sutrisno, Edy. 2013. Budaya Organisasi, Edisi ketiga, Jakarta: Kencana Prenadamedia Group.

Tjiptono, Fandy dan Gregorius Chandra. 2007. Pemasaran Strategik. Edisi Kedua. Yogyakarta: Penerbit Andi.

Umar, Husein. 2011. Metode Penelitian Untuk Skripsi Dan Tesis Bisnis. Jakarta: PT. Raja Grafindo Persada.

Usmara A. 2007. Strategi Baru Manajemen Pemasaran. Cetakan Pertama, Yogyakarta: Penerbit Amara Books.

Wibowo. 2016. Manajemen Kinerja. Edisi Lima. Cetakan Kesebelas. Jakarta: PT. Raja Grafindo Persada.

Widayati, R. (2019). Aktivitas Pemasaran Produk Simpanan PT. Bank Tabungan Negara (Persero)Tbk Kantor Cabang Padang. https://doi.org/10.17605/OSF.IO/3Z5YC 